\title{
Effects of Glycogen Synthase Kinase Inhibitor on Glioblastoma Multiforme Cell Line via Apoptosis and Cell Signaling Pathways
}

\author{
Mahmut CAMLAR ${ }^{1}$, Eda ACIKGOZ², Kenan DEMIR ${ }^{2}$, Aysegul UYSAL ${ }^{2}$, Fusun OZER ${ }^{1}$, Mehmet SELCUKI ${ }^{3}$, \\ Huseyin AKTUG² \\ ${ }^{1}$ University of Health Sciences, Tepecik Training and Research Hospital, Department of Neurosurgery, Izmir, Turkey \\ ${ }^{2} E$ ge University, Department of Histology and Embryology, Izmir, Turkey \\ ${ }^{3}$ Neurosurgeon in Private Practice, Izmir, Turkey
}

This study has been presented as an oral presentation at the World Federation of Neurosurgical Societies (WFNS) XVI World Congress of Neurosurgery between 20 and 25 August 2017 at Istanbul Convention Center in Istanbul, Turkey

Corresponding author: Mahmut CAMLAR drcamlar@gmail.com

\section{ABSTRACT}

AIM: To investigate the apoptotic and molecular effects of glycogen synthase kinase-3 (GSK-3) in glioblastoma multiforme (GBM). MATERIAL and METHODS: Human primary glioblastoma cell line (U-87 MG) and the human fetal glial cell line (SVGp12) were used. The cells were exposed to the different doses of GSK inhibitor for 24, 48 and 72 hours. Induction of apoptosis was assessed by DNA fragmentation (TUNEL) assay. EGFR and NF-kB expression was evaluated by immunofluorescence analyses.

RESULTS: GSK-3 inhibitor IX induced cytotoxicity and apoptosis in dose-dependent manner in GBM cells. Our results indicated that GSK-3 inhibitor IX induces apoptosis, resulting in a significant decrease in the expression of NF-kB and EGF.

CONCLUSION: Inhibition through GSK-3 has been found promising in creating therapeutic management of GBM cells. Proliferation, differentiation, cell cycle regulation, and apoptosis are mechanisms that must be interpreted as a whole. Components associated with EGFR, NF-kB, and apoptosis affect the mechanism solely and collectively. Our collective data suggest that GSK-3 inhibitor IX inhibited cellular proliferation and induced apoptotic events by modulating EGFR and NF-kB expression in GBM cells. GSK-3 inhibition holds promise for the development of new approaches for the therapeutic management of GBM cells.

KEYWORDS: Apoptosis, Cell signaling, Glioblastoma multiforme, Glycogen synthase kinase 3

ABBREVIATIONS: EGFR: Epidermal growth factor receptor, NF-kB: Nuclear factor kappa beta, GBM: Glioblastoma multiforme, SVGp12: Human fetal glial cell line, GSK-3: Glycogen synthase kinase-3, TMZ: Temozolomide, IC50: Half maximal inhibitory concentration, U-87 MG: Human primary glioblastoma cell line

\section{INTRODUCTION}

$\mathrm{G}$ lioblastoma multiforme (GBM) is known as the most common and most malignant primary brain tumor. Approximately 9.000 new cases are diagnosed globally every year (31). GBM consists of genotypically and phenotypically heterogeneous tumor groups and forms highly aggressive and invasive tumors. Patients diagnosed with glioblastoma survive less than 24 months, a recurrence of the tumor is almost guaranteed (17). Despite surgical
Mahmut CAMLAR (D): 0000-0002-6467-0172 Eda ACIKGOZ

Kenan DEMIR
(D) : 0000-0002-6772-3081

(D) : 0000-0003-2864-6041
Aysegul UYSAL

Fusun OZER

(D) : 0000-0002-9919-2254

(D) : 0000-0002-1625-5302

Mehmet SELCUKI (D) : 0000-0002-2310-3016
Huseyin AKTUG : 0000-0003-4150-8495 
treatment, chemotherapy, and radiotherapy which are the current treatment modalities, there remains no curative treatment for this disease. The major chemotherapeutic drug is an alkylating agent, Temozolomide (TMZ) (42). However, the administration of $\mathrm{TMZ}$ increases the median survival time of patients by only 2 months (7). Common pathways are disrupted by glioblastoma; therefore, stem cell pathways have been studied by many researchers and continue to be a major focus in cancer research centers worldwide.

Glycogen synthase kinase-3 (GSK-3) is a molecule involved in many cellular functions, including homeostasis, neuronal growth and differentiation, cell fate, metabolic homeostasis, development, microtubule function, and glycogen synthesis (27). The functions of apoptotic and antiapoptotic family members are regulated by GSK-3. GSK-3 $a$ and GSK-3 $\beta$ are two major isoforms of GSK-3 in mammals; both are common in the brain (13). These isoform structures are similar but functionally diverse. The presence of homologous GSK3 isoforms and their highly organized role in homeostasis make it difficult to target GSK-3. Studies have shown that the inactivation of GSK-3 with Akt or other phosphorylating agents is effective against cancer progression. Ougolkov et al. showed that GSK-3 inhibition decreased the proliferation of pancreatic cancer cells due to the inhibition of the GSK-3 $\beta$ mediated upregulation of NF-kB-mediated gene transcription (32). Similarly, studies of brain, colorectal, stomach, and bladder cancers obtained similar results by inhibiting GSK$3(28,30)$. All these studies suggest that GSK-3 should be a new therapeutic target in the treatment of human cancer, as it exhibited tumor-suppression behavior in these studies (28). Other studies have suggested that GSK-3 stabilizes the components of beta-catenin and may affect tumor progression (23). High glucose catabolism and glycolysis is characteristic of GBM cells when compared with healthy brain tissue. The inhibition of GSK-3 activity with the help of GSK-3 inhibitor molecules has been shown to reduce GBM cell survival and enhance apoptosis in a dose-dependent manner.

The appeal of GSK-3 for researchers is its involvement in many significant parts of the cellular pathways. Moreover, GSK-3 is not difficult to target in routine treatment. Genes involved in signaling pathways are susceptible to mutation, which may lead to multiple tumor types and/or tumor resistance (6). Therefore, it is possible to attenuate these pathways by targeting GSK-3 to improve cancer treatment responses. The PI3K-AKT-mTOR and RAS-MAPK pathways are activated in most glioblastomas (1). Programmed cell death, or apoptosis, is a key mechanism in tissue homeostasis in multicellular organisms (37), and it is one of the main factors affecting GBM. Specific morphological and biochemical characteristics have been observed in cells undergoing apoptosis (42). It is possible to fight cancer cells through apoptosis using a number of chemical agents. Mills et al. found that GSK-3 inhibition induced tumor cell death while protecting normal cells, making GSK-3 an important therapeutic target for brain tumor research (27).

NF-kB is a transcription factor that regulates many activities in the cell, such as the expression of genes that promote cell growth, viability, inflammation, and neoplastic transformation. NF-kB is composed of homodimers and heterodimers of the Rel family and is usually located in the cytoplasm in an inactive form induced by inhibitor IkBa. The active form of NF-kB acts as a transcription factor for target genes and can be induced by EGF, VEGF, and agents that damage DNA (34). In recent years, researchers have demonstrated NF-kB activation in GBM and have shown its mechanisms in pathogenesis. The epidermal growth factor receptor (EGFR) gene mutation is among the main genetic changes in GBM, and this mutation is the most important trigger of NF-kB. Several studies have shown the activation of NF-kB in various cell lines, emphasizing that $\mathrm{NF}-\mathrm{kB}$ is a negative marker for prognosis (20). NF-kB1/p50 is found mainly in the perinecrotic areas of the tumor, confirming that NF-kB is activated by hypoxia. In this context, NF-kB may have a critical role in the balance of the necrotic parts of GBM and apoptosis (5). NF-kB also plays a role in the molecular events of angiogenesis, indicating that pathways related to NF-kB and EGFR may be appropriate targets for the treatment of GBM which is known for its high vascularity.

EGFR is a transmembrane receptor tyrosine kinase that is important for normal development. Because EGFR is mutated in many cancers, including GBM, many researchers have tried to fight cancer by targeting EGFR. Tyrosine kinase inhibitors (TKIs), which target signal transduction against EGFR, have been defined as anti-tumor agents. EGFR has been used alone or in combination with chemotherapeutic agents for the treatment of many cancer types including colorectal and pancreatic cancers (among others), but it has not been used routinely in the treatment of gliomas (44). In all large cancer studies, EGFR has been defined to have a key role in the treatment of GBM $(33,39)$. However, the blood-brain barrier seems to be the main obstacle to the ability of EGFR to target glioblastoma. In this context, treatment with many molecules has been attempted; however, clinically expected benefits have not been demonstrated (34).

Recently, emerging evidence has shown that GSK-3 plays a pivotal role in cell proliferation, resistance to therapy, and the prevention of apoptosis in GBM cells. Thus, it is important to investigate and discover new molecularly targeted drugs that effectively kill GBM cells. The first aim of the current study was to investigate the effects of GSK-3 inhibitor IX on GBM cells. We also aimed to illuminate the molecular mechanisms underlying the action of the drug.

\section{MATERIAL and METHODS}

\section{Cell Culturing Conditions and Reagents}

SVGp12 (ATCC CRL-8621, Manassas, VA, USA) and U-87MG (ATCC HTB-14) were purchased from the American Type Culture Collection (ATCC). Cells were cultured in Eagle's Minimum Essential Medium (EMEM) (ATCC 30-2003) containing 10\% $(\mathrm{v} / \mathrm{v})$ heat-inactivated fetal calf serum (Biological Industries, Kibbutz Beit Haemek, Israel), 100 units of penicillin-streptomycin/ml (Biological Industries), 1\% L-glutamine (Biological Industries) at $37^{\circ} \mathrm{C}$ in humidified atmosphere containing $5 \%$ $\mathrm{CO}_{2}$. GSK-3 inhibitor IX was obtained from Santa Cruz (sc- 
202634, Santa Cruz Biotechnology, Inc., Santa Cruz, CA, USA) and dissolved in dimethyl sulfoxide (DMSO). The DMSO concentration did not exceed $0.1 \%$ and was not cytotoxic to the tumor cells. The antibodies used were antiNF-kB p105/ p50 (1:50 diluted; AM06029FC-N, OriGene Technologies, Rockville, MD), antiEGFR (1:50 diluted; TA303484, OriGene Technologies) and FITC Conjugated Goat Anti-Rabbit IgG (1:100 diluted; TA130022, OriGene Technologies). We obtained an ApopTag Plus Peroxidase In Situ Apoptosis Kit (S7101) for terminal deoxynucleotidyl transferase-mediated dUTP nicklabeling (TUNEL) from the Millipore Corporation (Billerica, MA).

\section{Experimental Groups}

Group 1: Glioblastoma multiforme (GBM) [U-87MG (ATCC HTB-14 TM)]

Group 2: Human fetal glial cell line [SVGp12 (ATCC CRL-8621)]

Group 3: GBM + GSK-3 (glycogen synthase kinase) inhibitor

Group 4: Human fetal glial cell line + GSK-3 (glycogen synthase kinase) inhibitor

These experimental groups were incubated for 24,48 , and 72 hours following administration of 0.5-, 1-, 1.5-, 2-, and 2.5$\mu \mathrm{M}$ doses of GSK-3 inhibitor IX to examine its IX effects. The effects of GSK-3 inhibitor IX on cell viability (apoptosis) were investigated.

\section{Cytotoxicity Assay}

The quantitative determination of viable cells following treatment with GSK-3 inhibitor IX was performed using the Muse ${ }^{\circledR}$ Count and Viability kit (Muse ${ }^{\circledR}$ Cell Analyzer; Millipore) according to the manufacturer's protocol. Briefly, SVGp12 and U-87MG cells were seeded into six-well plates at a density of $3 \times 10^{5} \mathrm{cells} /$ well and grown for 24 hours at $37^{\circ} \mathrm{C}$ in a humidified $5 \% \mathrm{CO}_{2}$ incubator. Cells were then treated with increasing doses of GSK-3 inhibitor IX $(0.5,1,1.5,2$, and $2.5 \mu \mathrm{M})$ for 24 , 48 , and 72 hours. After incubation, all cells were collected and diluted with phosphate-buffered saline (PBS). We added $50 \mu \mathrm{l}$ of cell suspension to $450 \mu \mathrm{l}$ Muse ${ }^{\circledR}$ Count and Viability reagent, incubated it for 5 minutes at room temperature, and performed analysis using the Muse ${ }^{\circledR}$ Cell Analyzer. Data arereported as proportional viability (\%), calculated by comparing the GSK-3 inhibitor IX treatment group with untreated cells, the viability of which was assumed to be $100 \%$.

\section{Immunofluorescence Staining}

Following treatment with GSK-3 inhibitor IX, cells were placed on lysine-coated coverslips and fixed in $4 \%$ paraformaldehyde for 15 minutes. The cells were then permeabilized with $0.1 \%$ Triton X100/PBS for $10 \mathrm{~min}$ at room temperature and blocked with PBS containing 5\% bovine serum albumin for 1 hour. To detect NF-kB p105/p50 and EGFR, cells were incubated with the primary antibody overnight at $4^{\circ} \mathrm{C}$. After washing with PBS, cells were treated with secondary antibody for 1 hour at room temperature in a humidified chamber. Finally, the immunostained cells were mounted in mounting medium containing 4',6-diamidino-2-phenylindole (DAPI) and visualized using a fluorescence microscope equipped with a camera (Olympus BX51, Olympus C5050 digital test).

\section{TUNEL Assay}

Apoptosis was confirmed by a TUNEL assay in GSK-3 inhibitor IX treatment cells for 48 hours. The ApopTag Plus Peroxidase In Situ Apoptosis Detection Kit was used according to the manufacturer's protocol to detect cell death. Briefly, cells were sub-cultured in six-well plates and incubated for 24 hours at $37^{\circ} \mathrm{C}$ and $5 \% \mathrm{CO}_{2}$. The cells were then treated with GSK3 inhibitor IX. After treatment, the cells were fixed with $4 \%$ paraformaldehyde for 15 minutes at $4^{\circ} \mathrm{C}$ and rinsed twice with PBS.

\section{Statistical Analysis}

We performed one-way analysis of variance (ANOVA) followed by a Tukey's or Dunett's post hoc test to identify significant differences between treatment groups receiving increasing concentrations of GSK-3 IX inhibitor and positive controls in terms of cytotoxic effect percentage.

\section{RESULTS}

\section{Cytotoxic Effects of GSK-3 Inhibitor IX}

We studied the effects of GSK-3 inhibitor IX on cell viability at increasing doses $(0.5-2.5 \mu \mathrm{M})$ and time $(24,48$, and 72 hours) in the SVGp12 and U-87MG lines. After 24 hours of treatment with GSK-3 inhibitor IX, concentrations of $0.5-2.5 \mu \mathrm{M}$ were not significantly cytotoxic $(p>0.05)$ in the SVGp12 cell line at doses between 0.5 and $1.5 \mu \mathrm{M}$ when compared with the control. The cytotoxic effects at doses of 2 and $2.5 \mu \mathrm{M}$ were statistically significant when compared with the control $(p<0.05)$. The cytotoxic effects at 0.5-, 1-, 1.5-, 2-, and 2.5- $\mu \mathrm{M}$ concentrations at 48 hours were calculated and are shown in Figure $1 \mathrm{~A}-\mathrm{F}$. The difference in the cytotoxic effects of 1 and $1.5 \mu \mathrm{M}$ was not statistically significant $(p>0.05)$; however, the differences in the effects of other dose-based comparisons were statistically significant $(p<0.001)$. The cytotoxic effect at 72 hours was statistically significant $(p<0.001$, Figure $3 A$, B) compared to the control. Using these data, we did not determine the IC50 values of GSK-3 inhibitor IX for 24 and 48 $h$ in the SVGp12 cell line, and the IC50 value for 72 hours was $2.2 \pm 0.02 \mu \mathrm{M}$ (Figures 1A-F; 2A-F; 3A, B).

The cytotoxic effect was statistically significant $(p<0.001)$ when the concentrations of GSK-3 inhibitor IX administered to the U-87MG cell line were compared with those administered to the controls at 0.5 and $2.5 \mu \mathrm{M}$ at 24,48 , and 72 hours (Figures $2 A-F ; 3 A, B)$. The IC50 values for 24,48 , and 72 hours in the GSK-3 inhibitor IX treatment of the U87MG cell line were 2.3 $\pm 0.3,2.05 \pm 0.32(p<0.001)$, and $1.4 \pm 0.01 \mu \mathrm{M}$, respectively.

\section{Immunofluorescence Results}

Changes in NF-kB p105/p50 and EGFR in SVGp-12 and U-87MG cells treated with GSK-3 inhibitor IX were determined by immunofluorescence staining. Cells were treated with GSK-3 inhibitor IX at a dose of $2.05 \mu \mathrm{M}$ for 48 hours. GSK-3 inhibitor IX was not added in the control group. We observed no difference in the amount of fluorescence in the EGF protein in SVGp12 when compared to the control group (Figure 4A-D). 


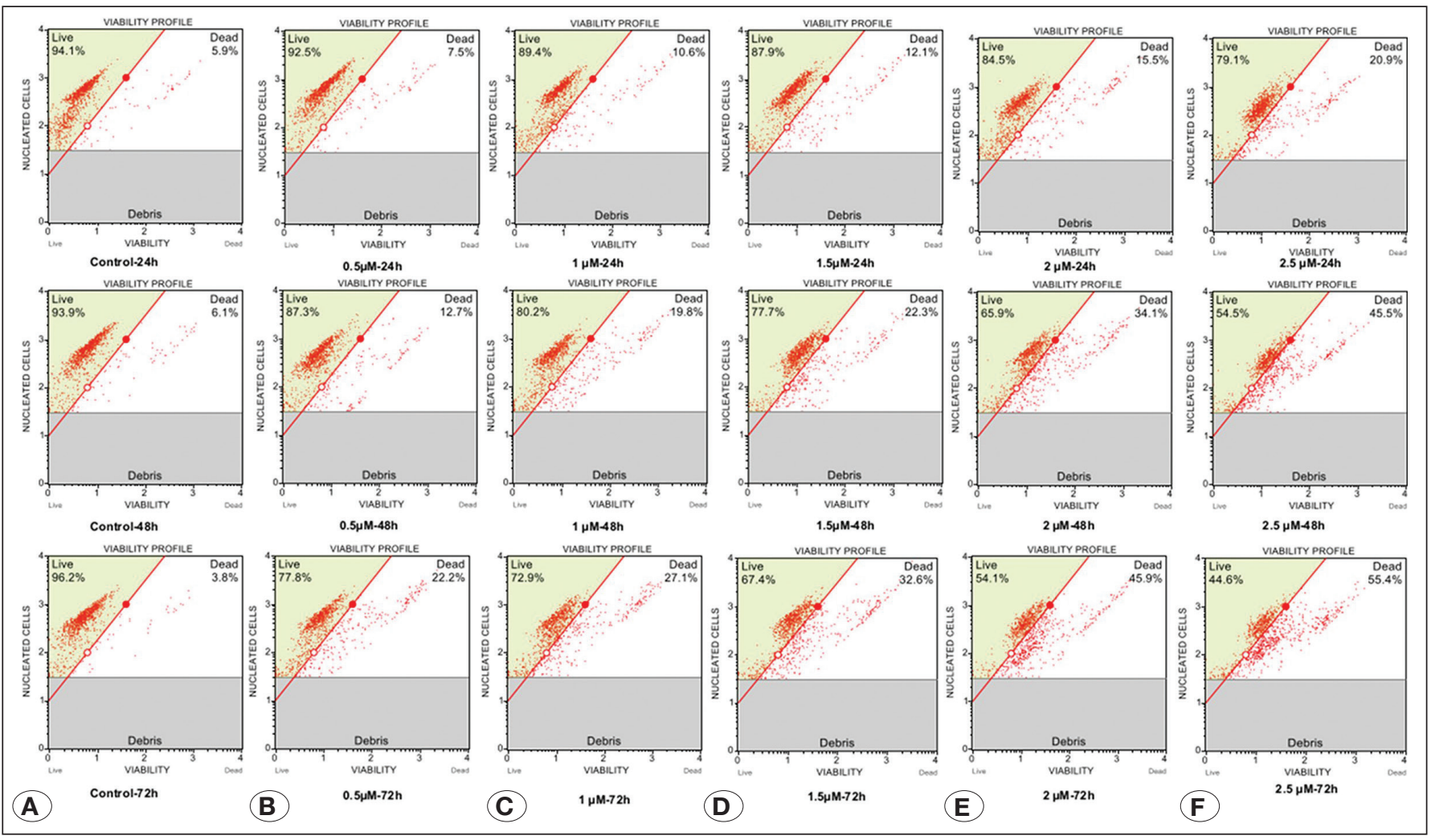

Figure 1: Cell viability profile of SVGp12 cells obtained by administration of different doses of GSK-3 inhibitor (A: control, B: $0.5 \mu M$, C: $1 \mu \mathrm{M}$, D: $1.5 \mu \mathrm{M}$, E: $2 \mu \mathrm{M}$, and F: $2.5 \mu \mathrm{M})$ at different times (24, 48, and 72 hours).

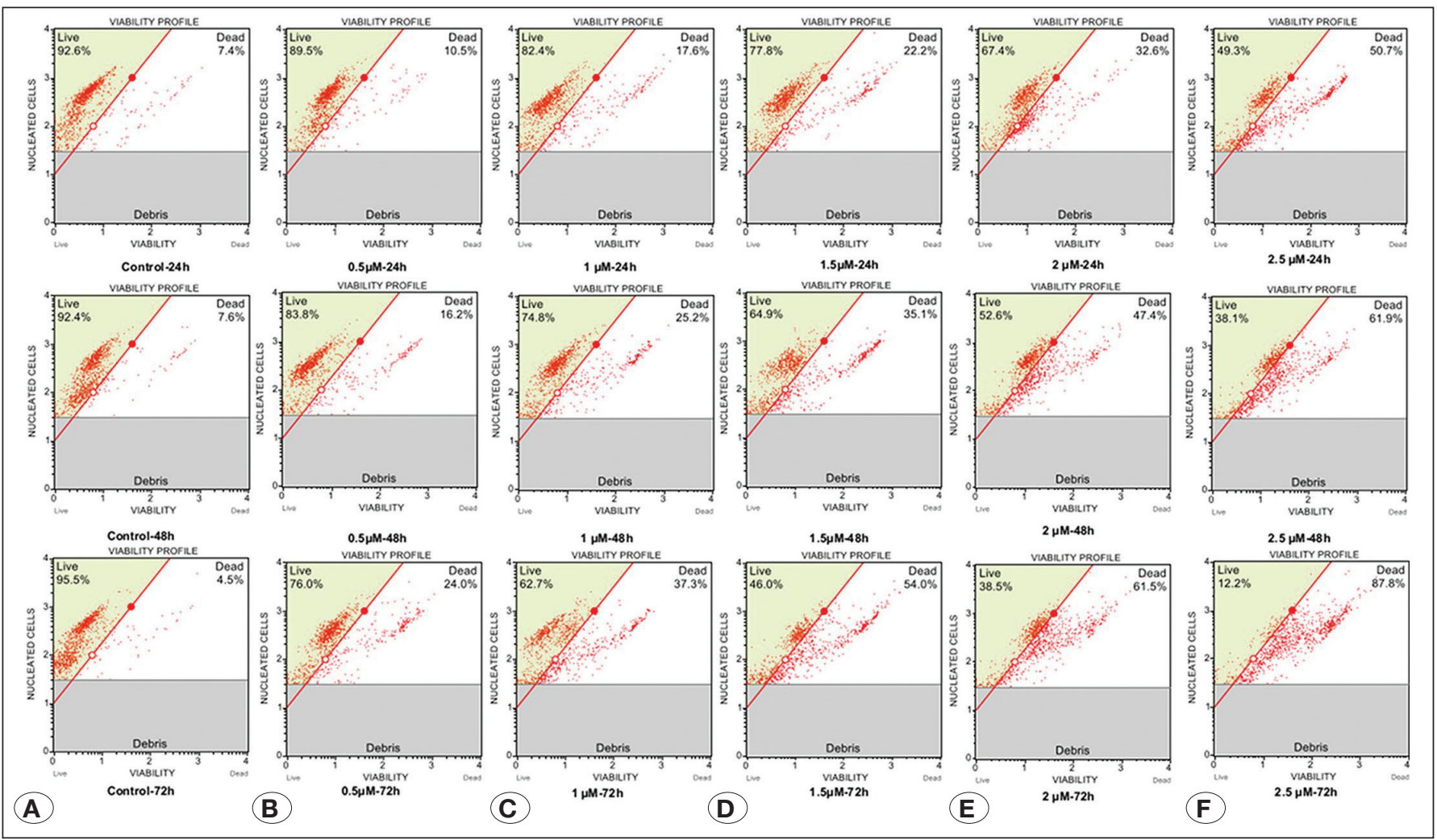

Figure 2: Cell viability profile of U87 MG cells obtained by administration of different doses of GSK-3 inhibitor (A: control, B: $0.5 \mu M$, C: $1 \mu \mathrm{M}, \mathbf{D}: 1.5 \mu \mathrm{M}$, E: $2 \mu \mathrm{M}$, and F: $2.5 \mu \mathrm{M})$ at different times (24, 48, and 72 hours). 
EGF expression was higher inthe U-87MG cell line than in SVGp12. The administration of the GSK-3 inhibitor reduced EGF expression in GBM. In the control groups, NF-kB expression decreased following drug administration. When GBM was compared with human fetal glial cell lines, we observed an increase in NF-kB expression. As a result of drug administration in the GBM line, NF-kB expression decreased (Figure 4A-D).

\section{TUNEL Staining Results}

Apoptosis was observed in both human fetal glial cells and GBM cells as a result of the administration of the GSK-3 inhibitor in the TUNEL assay. The apoptosis rate was higher in the glioblastoma cell line (Figure 5).

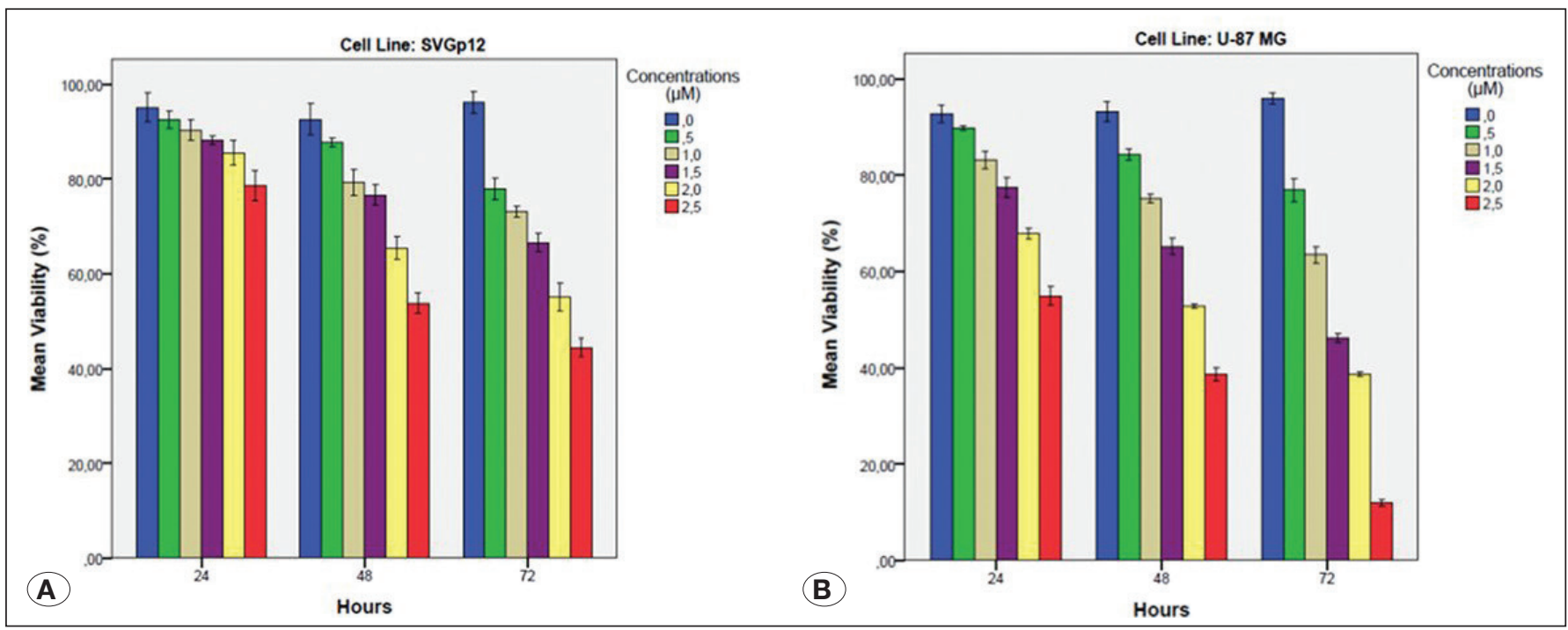

Figure 3: Statistical analysis of the effects of GSK-3 inhibitor IX on cell viability (\%) over time in (A) the SVGp12 cell line and (B) the U 87MG cell line.

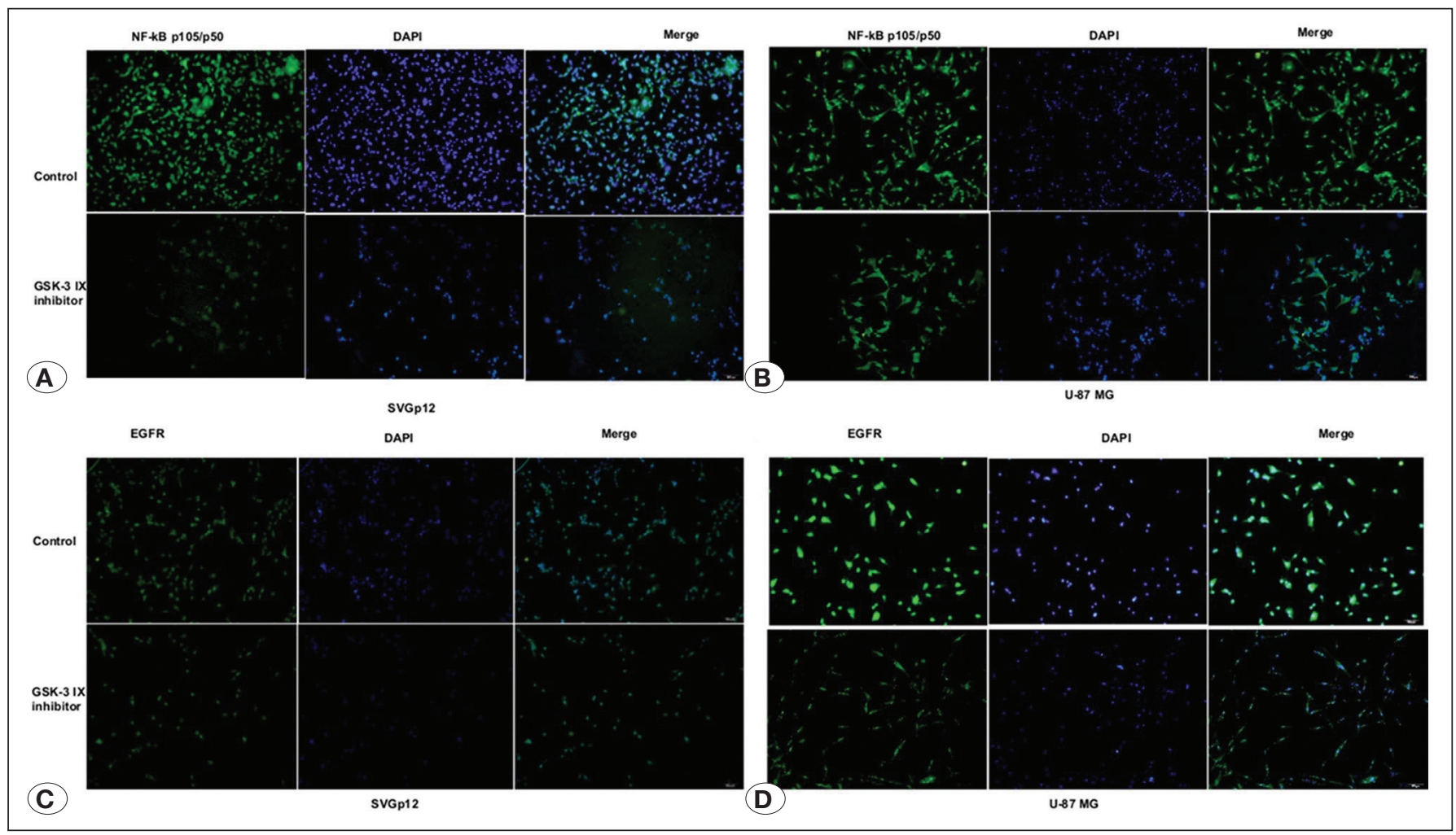

Figure 4: Fluorescence microscope image of the change in; (A-B) the NF-kB p105/p50 protein and, (C-D) the EGFR protein in cell lines (A-C: SVGp12, B-D: U-87 MG) treated with GSK-3 inhibitor IX in 2.05- $\mu \mathrm{M}$ doses for 48 hours (scale bar: $100 \mu \mathrm{m}$ ). 


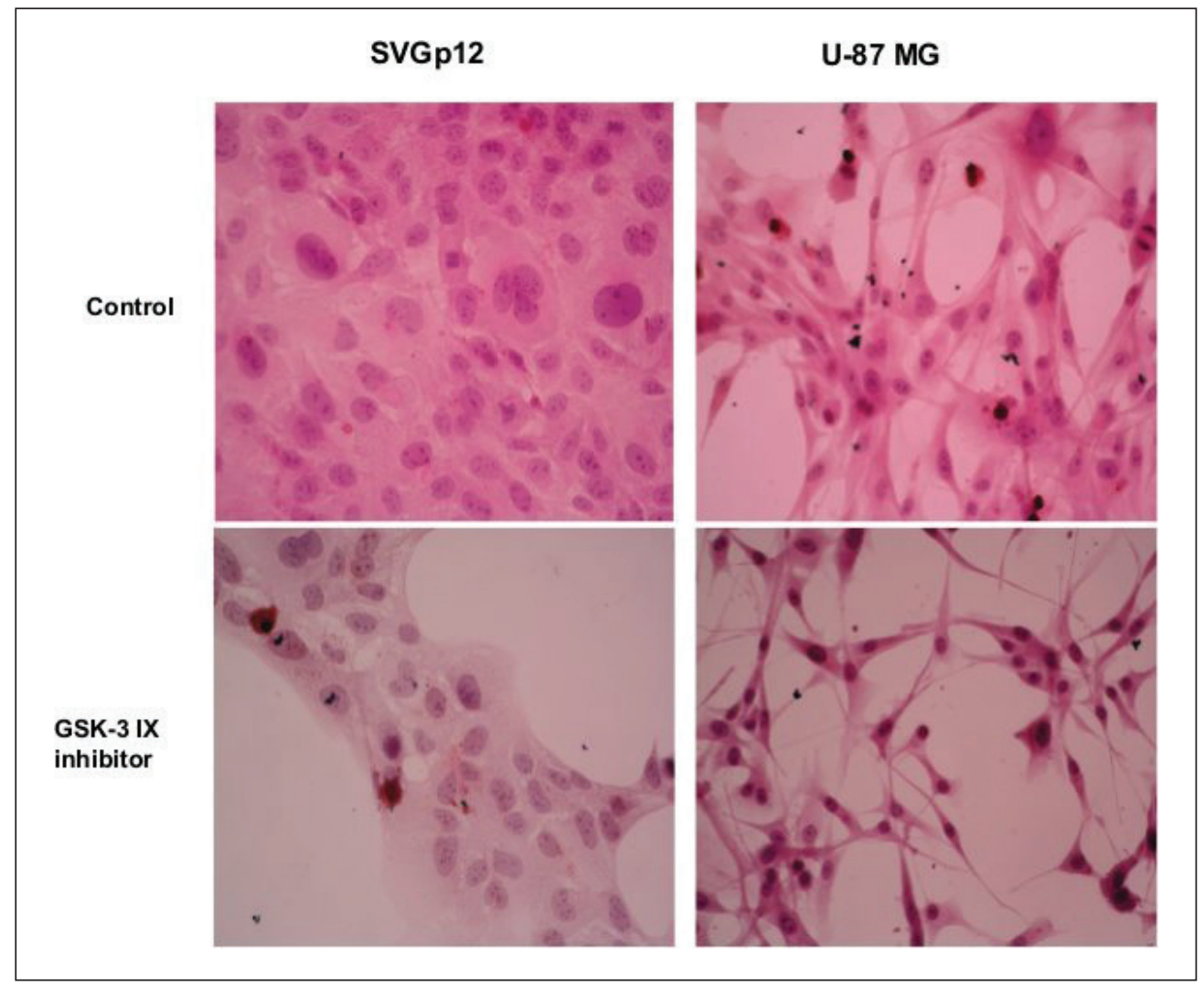

Figure 5: Terminal deoxynucleotidyl transferasemediated dUTP nick-labeling (TUNEL) assay results in SVGp12 and $\mathrm{U}-87 \mathrm{MG}$ cell lines treated with GSK-3 inhibitor IX in 2.05$\mu \mathrm{M}$ doses for 48 hours.

\section{DISCUSSION}

GBM is the most common type of malignant brain tumor. During GBM development, loss of control in the G1/S phase of the cell cycle and the $10 \mathrm{q}$ chromosome loss mutation in the EGFR, FGFR2, and AKT3 genes lead to PTEN mutation (38). Despite innovations in treatment regimens consisting of surgical techniques followed by chemoradiotherapy, the average life expectancy of GBM patients is 12-14 months. Unfortunately, current treatment options are inadequate for glioblastoma therapy, with no significant change in survival rates. Technological developments have contributed to a better understanding of the underlying genetic and molecular mechanisms of the disease and have allowed for the development of new therapeutic strategies. TMZ is the first-line chemotherapeutic drug; however, its efficacy is limited due to the genetic heterogeneity of GBM cells $(10,40)$. Weyhenmeyer et al. reported that cell death following the administration of TMZ depended on the apoptotic effect of the drug (41). Defects in the signal pathways, particularly the apoptotic pathway, cause normal cell growth and proliferation. One of the main goals in the treatment of GBM is the development of potential molecules that induce the apoptotic pathway. Recent studies have suggested that the overexpression of GSK-3 promotes cell survival in GBM. In this study, we hypothesized that GSK3 inhibition could induce apoptosis in GBM cells through modulation of the NFkB and EFFR pathways. Our results demonstrate that GSK-3 inhibitor IX induced growth inhibition and apoptosis in GBM cells.
Higher GSK-3 expression levels have been found in GBM when compared with non-neoplastic brain tissues (29). Some studies have shown that the inactivation of GSK-3 by Akt or other phosphorylating agents indicates cancer progression and that Akt behaves as a tumor suppressor gene; however, it exhibits oncogenic behavior. Although this effect has not been demonstrated by animal experiments, the use of GSK-3 in routine cancer treatment has produced ambiguous results. Additionally, no increase in the incidence of cancer has been observed in patients who suffer from mood disorders and depression who have been medicated with lithium, a GSK-3 inhibitor (41). The dysregulation of GSK activity has also been associated with many diseases, including cancer, diabetes, and various neurological diseases (24). GSK-3 has been associated with a number of signaling pathways regulating the survival and proliferation of cancer cells (45). Several studies have shown that GSK-3 inhibition induces apoptosis in cancer cells. Lithium is an ATP non-competitive inhibitor of GSK-3 $\beta$ activity that has been widely used in many studies as a regulator of GSK-3 $\beta$ signaling pathways $(2,3,9,16)$. Lithium directly inhibits GSK-3 and induces apoptosis by activating NFAT1/FasL (3). Chou et al. and Aras et al. reported that a Lithium concentration of $45 \mathrm{mM}$ can affect the proliferation, apoptosis, and migration of glioma cells via GSK-3 inhibition; however, this concentration can cause brain damage $(2,9)$. Gomez-Sintes and Lucas (16) similarly reported that Lithium induced nuclear translocation of NFATs, increased FasL levels, and led to apoptosis in neurons via the inhibition of 
GSK-3 activity. Recently, it has been reported that Lithium is not a selective GSK-3 inhibitor and it is very difficult to control the complications caused by various additional activities (11). This fact points to a new potential GSK-3 inhibitor for treatment of GBM. In the present study, we describe a novel GSK-3 inhibitor IX which shows robust antitumor activity in vitro. GSK-3 inhibitor IX is a selective, cell-permeable and reversible inhibitor of GSK-3a and GSK-3 $\beta$ (25). Our result shave shown that GSK-3 inhibitor IX has cytotoxic effects on GBM cells. In addition, GSK-3 inhibitor IX promoted apoptosis in both the SVGp12 and U-87 MG cell lines. However, the apoptosis rate was much greater in the U-87 MG cell line than in SVGp12. The inhibition of GSK-3 has also been shown to promote apoptosis in neuroblastoma, prostate, pancreatic, and colorectal cancer cell lines (27). Miyashita et al. also reported that GSK-3 inhibition suppresses glioblastoma cell viability and proliferation and induces apoptosis (29).

With the discovery of the regulation of NF-kB with GSK-3 and the antiproliferative effects of its inhibition, it was thought that the inhibition of NF-kB could be used in cancer treatment (18). NF-kB is an important regulator of inflammation, cell viability, and immunity and is associated with numerous cellular activities. NF-kB signaling pathways can be triggered by numerous cytokine stimuli, including TNF alpha, IL-1 beta, pathogen-associated molecular patterns, ionizing and ultraviolet radiation, reactive oxygen species, growth factors, DNA damage, and oncogenic stress $(14,26)$. It plays an important role in the survival of glioma cells. The activation of NF-kB has been implicated in resistance to apoptosis-based chemotherapy in glioblastoma and many cancer types $(19,22)$. Hence, the inhibition of NF-kB activity by specific molecules down regulates the expression of antiapoptotic genes activated by NF-kB and thus induces apoptosis sensitivity in GBM cells. Gill et al. reported that the inhibition of NF-kB by sulfasalazine increased apoptosis in glioma cells (15). The activation of NF-kB in GBM has been shown to promote the growth and survival of tumor cells $(14,35)$. It has also been shown that NF-kB induces cancer development and tumor progression by inducing a proinflammatory microenvironment and even leads to chemotherapy resistance $(4,43)$. NF-kB regulates protein transcription for the down-regulation of apoptosis and increases cell invasion, angiogenesis, and vascular permeability in the cell nucleus (12). Chin et al. reported the neuroprotector effect of GSK-3 inhibition in that it reduces neuronal death (8). Our study also showed a statistically significant increase in the expression of NF-kB in GBM cells when comparing GBM and normal brain cell lines. In preclinical studies, other agents, either with or without TMZ as a chemotherapeutic agent, have also targeted NF-kB (14). Our results indicate that GSK-3 inhibitor treatment decreases the expression of NF-kB and induces apoptosis. It provides in sights into the mechanism of apoptosis induction mediated by GSK-3 inhibitor IX in GBM cells. The EGFR gene mutation is one of the main genetic changes in GBM and triggers NF-kB. Thus, it is highly likely that this GSK-3 inhibitor will also affect EGFR expression.

EGFR is a cell surface receptor and a mutation affecting EGFR expression may result in cancer (21). High EGFR expression has been detected in mutations of cancers, such as GBM, anal cancers, and lung cancer. These somatic mutations, which are also affected by EGFR, result in uncontrolled cell division $(15,37)$. The most frequent genetic change is over expression in EGFR amplification and/or protein level, which is observed in $40-60 \%$ of cases (22). Specific mutations of EGFR, more or less referred to as EGFRvill, are frequently observed in GBM (8). Therefore, EGFR is thought to be an important pathway in a therapeutic strategy against GBM. EGFRvIII has been shown to enhance angiogenesis in studies of GBM in vivo (34). EGFR family proteins play an important role in proliferation, differentiation, and survival. EGFR expression in GBM is associated with increased proliferation and migration $(2,22)$. The relationship between EGFR and the migration of GBM cells offers an opportunity for treatment. In our study, EGF expression was found to be higher in the U-87MG cell line than in SVGp12. The activation of GSK-3 in cancer may be related to EGFR pathways. The high expression of both NF-kB and EGFR in GBM cells suggests that these two pathways may be related to each other (36). EGFR induces the NF-kB signaling pathway through the proteasome-mediated degradation of the inhibitory molecule IkB (36). Our results show that the administration of GSK-3 inhibitor IX to the GBM cell line reduced EGFR expression.

\section{- CONCLUSION}

The low success rate of current GBM treatment protocols is leading researchers to focus on the pathogenesis and cellular signaling pathways of this disease. In the present study, we attempted to elucidate the effects of GSK-3 inhibition and to illuminate changes in the signaling pathways. NF-kB and EGFR play an important role in the survival of glioma cells, such that the inhibition of GSK-3 attenuates NF-kB and EGFR, leading to a decrease in glioma cell growth. Additionally, the results of this study can be used to identify and diagnose GBM cases at the molecular level and to develop follow-up research. Our results also encourage researchers to administer GSK3 inhibitors to GBM patients to target the NF-kB and EGFR pathways. Proliferation, differentiation, cell cycle regulation, and apoptosis are mechanisms that must be analyzed as a whole system. Inhibition through GSK is a promising approach for the creation of new therapies.

\section{ACKNOWLEDGEMENT}

This experimental study was supported by Ege University scientific research project funding (Project number: 16 TIP 039).

\section{REFERENCES}

1. Aldape K, Zadeh G, Mansouri S, Reifenberger G, von Deimling A: Glioblastoma: Pathology, molecular mechanisms and markers. Acta Neuropathol 129:829-848, 2015

2. Aras $Y$, Erguven M, Aktas E, Yazihan N, Bilir A: Antagonist activity of the antipsychotic drug lithium chloride and the antileukemic drug imatinib mesylate during glioblastoma treatment in vitro. Neurol Res 38:766-774, 2016 
Camlar M. et al: Effects of GSK-3 Inhibitor on GBM Cell Line

3. Ayton S, Lei P: The Aß-induced NFAT apoptotic pathway is also activated by GSK-3 inhibition: Implications for Alzheimer therapeutics. J Neurosci 32: 9454-9456, 2012

4. Baud V, Karin M: Is NF-kappaB a good target for cancer therapy? Hopes and pitfalls. Nature Reviews Drug Discovery 8:33-40, 2009

5. Bharti AC, Aggarwal BB: Nuclear factor-kappa B and cancer: Its role in prevention and therapy. Biochem Pharmacol 64:883-888, 2002

6. Brugge J, Hung MC, Mills GB: A new mutational AKTivation in the PI3K pathway. Cancer Cell 12:104-107, 2007

7. Chang L, Su J, Jia X, Ren H: Treating malignant glioma in Chinese patients: Update on temozolomide. Onco Targets Ther 12:235-244, 2014

8. Chin PC, Majdzadeh N, D'Mello SR: Inhibition of GSK-3 beta is a common event in neuroprotection by different survival factors. Brain Res Mol Brain Res 13:193-201, 2005

9. Chou $\mathrm{CH}$, Chou AK, Lin CC, Chen WJ, Wei CC, Yang MC, Hsu CM, Lung FW, Loh JK, Howng SL, Hong YR: GSK-3beta regulates Bcl2L12 and Bcl2L12A anti-apoptosis signaling in glioblastoma and is inhibited by LiCl. Cell Cycle 11: 532-542, 2012

10. Cloughesy TF, Cavenee WK, Mischel PS: Glioblastoma: From molecular pathology to targeted treatment. Annu Rev Pathol 9: 1-25, 2014

11. Coghlan MP, Culbert AA, Cross DA, Corcoran SL, Yates JW, Pearce NJ, Rausch OL, Murphy GJ, Carter PS, RoxbeeCox L, Mills D, Brown MJ, Haigh D, Ward RW, Smith DG, Murray KJ, Reith AD, Holder JC: Glycogensynthase kinases-3beta controls differentiation of malignant glioma cells. Int $\mathrm{J}$ Cancer 127:1271-1282, 2010

12. Deighton RF, Le Bihan T, Martin SF, Barrios-Llerena ME, Gerth AM, Kerr LE, McCulloch J, Whittle IR: The proteomic response in glioblastoma in young patients. J Neurooncol 119(1):79-89, 2014

13. Doble B, Woodgett JR: GSK-3: Tricks of the trade for a multitasking kinase. J Cell Sci 1:1175-1186, 2003

14. Friedmann-Morvinski D, Narasimamurthy $R$, Xia $Y$, Myskiw C, Soda Y, Verma IM: Targeting NF-kB in glioblastoma: A therapeutic approach. Sci Adv 2(1): e1501292, 2016

15. Gill JS, Zhu X, Moore MJ, Lu L, Yaszemski MJ, Windebank AJ: Effects of NFkappaB decoy oligonucleotides released from biodegradable polymer microparticles on a glioblastoma cell line. Biomaterials 23:2773-2781, 2002

16. Gomez-Sintes R, Lucas JJ: NFAT/Fas signaling mediates the neuronal apoptosis and motor side effects of GSK-3 inhibition in a mouse model of lithium therapy. J Clin Invest 120: 24322445, 2010

17. Grossman SA, Batara JF: Current management of glioblastoma multiforme. Semin Oncol 31:635-644, 2004

18. Hoeflich KP, Luo J, Rubie EA, Tsao MS, Jin O, Woodgett JR: Requirement for glycogen synthase kinase-3beta in cell survival and NF-kappaB activation. Nature 406:86-90, 2000

19. Karin M: Nuclear factor-nB in cancer development and progression. Nature 25:431-436, 2006
20. Korkolopoulou P, Levidou G, Saetta AA, El-Habr E, Eftichiadis C, Demenagas P, Thymara I, Xiromeritis K, Boviatsis E, Thomas-Tsagli E, Panayotidis I, Patsouris E: Expression of nuclear factor-kB in human astrocytomas: Relation to plkBa, vascular endothelial growth factor, Cox-2, microvascular characteristics, and survival. Human Pathology 39:11431152, 2008

21. Kovacsics CE, Gottesman, Gould TD: Lithium's antisuicidal efficacy: Elucidation of neurobiological targets using endophenotype strategies. Annu Rev Pharmacol Toxicol 49: 175-198, 2009

22. Lefranc F, Brotchi J, Kiss R: Possible future issues in the treatment of glioblastomas: Special emphasis on cell migration and the resistance of migrating glioblastoma cells to apoptosis. J Clin Oncol 23:2411-2422, 2005

23. Li Y, Lu H, Huang Y, Xiao R, Cai X, He S, Yan G: Glycogen synthase kinase-3 $\beta$ controls differentiation of malignant glioma cells. Int J Cancer 127:1271-1282, 2010

24. McCubrey JA, Steelman LS, Bertrand FE, Davis NM, Sokolosky M, Abrams SL, Montalto G, D'Assoro AB, Libra M, Nicoletti F, Maestro R, Basecke J, Rakus D, Gizak A, Demidenko ZN, Cocco L, Martelli AM, Cervello M: GSK-3 as potential target for therapeutic intervention in cancer. Oncotarget 5:28812911, 2014

25. Meijer L, Skaltsounis AL, Magiatis P, Polychronopoulos $P$, Knockaert M, Leost M, Ryan XP, Vonica CA, Brivanlou A, Dajani R, Crovace C, Tarricone C, Musacchio A, Roe SM, Pearl L, Greengard P: GSK-3-selective inhibitors derived from Tyrian purple indirubins. Chem Biol 10:1255-1266, 2003

26. Mieczkowski J, Kocyk M, Nauman P, Gabrusiewicz K, Sielska M, Przanowski P, Maleszewska M, Rajan WD, Pszczolkowska D, Tykocki T, Grajkowska W, Kotulska K, Roszkowski M, Kostkiewicz B, Kaminska B: Down-regulation of IKK expression in glioma-infiltrating microglia/macrophages is associated with defective inflammatory/immune gene responses in glioblastoma. Oncotarget 6:33077-33090, 2015

27. Mills CN, Nowsheen S, Bonner JA, Yang ES: Emerging roles of glycogen synthase kinase 3 in the treatment of brain tumors. Front Mol Neurosci 25:47, 2011

28. Mishra R: Glycogen synthase kinase 3 beta: Can it be a target for oral cancer? Mol Cancer 9:144, 2010

29. Miyashita K, Kawakami K, Nakada M, Shakoori A, Fujisawa H, Hayashi Y, Hamada Ji, Minamoto T: Potential therapeutic effect of glycogen synthase kinase 3B inhibition against human glioblastoma. Clin Cancer Res 15:887-897, 2009

30. Naito S, Bilim V, Yuuki K, Ugolkov A, Motoyama T, Nagaoka A, Kato T, and Tomita, Y: Glycogen synthase kinase-3beta: A prognostic marker and a potential therapeutic target in human bladder cancer. Clin Cancer Res 16:5124-5132, 2010

31. Ohgaki H: Genetic pathways to glioblastomas. Neuropathology 25:1-7, 2005

32. Ougolkov AV, Fernandez-Zapico ME, Savoy DN, Urrutia RA, Billadeau DD: Glycogen synthase kinase-3beta participates in nuclear factor kappaB-mediated gene transcription and cell survival in pancreatic cancer cells. Cancer Res 65:2076-2081, 2005 
33. Padfield E, Ellis HP, Kurian KM: Current therapeutic advances targeting EGFR and EGFRvIll in glioblastoma. Front Oncol 29:5, 2015

34. Puliyappadamba VT, Hatanpaa KJ, Chakraborty S, Habib AA: The role of NF-kB in the pathogenesis of glioma. Mol Cell Oncol (3): e963478, 2014

35. Robe PA, Bentires-Alj M, Bonif M, Rogister B, Deprez M, Haddada $\mathrm{H}$, Khac MT, Jolois O, Erkmen K, Merville MP, Black $\mathrm{PM}$, Bours V: In vitro and in vivo activity of the nuclear factorkappaB inhibitor sulfasalazine in human glioblastomas. Clin Cancer Res 10:5595-5603, 2004

36. Shostak K, Chariot A. EGFR and NF-kB: Partners in cancer. Trends Mol Med 21:385-393, 2015

37. Tsujimoto Y, Shimizu S: Another way to die: Autophagic programmed cell death. Cell Death Differ 12 Suppl 2:15281534, 2005

38. Urbańska K, Sokołowska J, Szmidt M, Sysa P: Glioblastoma multiforme: An overview. Contemp Oncol 18:307-312, 2014

39. Verhaak RG, Hoadley KA, Purdom E, Wang V, Qi Y, Wilkerson MD, Miller CR, Ding L, Golub T, Mesirov JP, Alexe G, Lawrence M, O'Kelly M, Tamayo P, Weir BA, Gabriel S, Winckler W, Gupta S, Jakkula L, Feiler HS, Hodgson JG, James CD, Sarkaria JN, Brennan C, Kahn A, Spellman PT, Wilson RK, Speed TP, Gray JW, Meyerson M, Getz G, Perou CM, Hayes DN: Integrated genomic analysis identifies clinically relevant subtypes of glioblastoma characterized by abnormalities in PDGFRA, IDH1, EGFR, and NF1. Cancer Cell 17:98-110, 2010
40. Weller M, van den Bent M, Hopkins K, Tonn JC, Stupp R, Falini A, Cohen-Jonathan-Moyal E, Frappaz D, Henriksson R, Balana C, Chinot O, Ram Z, Reifenberger G, Soffietti R, Wick W: EANO guideline for the diagnosis and treatment of anaplastic gliomas and glioblastoma. Lancet Oncol 15:395403, 2014

41. Weyhenmeyer BC, Noonan J, Wurstle ML, Lincoln FA, Johnston G, Rehm M, Murphy BM: Predicting the cell death responsiveness and sensitization of glioma cells to TRAIL and temozolomide. Oncotarget 7:61295-61311, 2016

42. Wu WS, Chien CC, Liu KH, Chen YC, Chiu WT: Evodiamine prevents glioma growth, induces glioblastoma cell apoptosis and cell cycle arrest through JNK activation. Am J Chin Med 45(4): 879-899, 2017

43. Xia Y, Shen S, Verma IM: NF-kB, an active player in human cancers. Cancer Immunol Res 2(9):823-830, 2014

44. Yewale C, Baradia D, Vhora I, Patil S, Misra A: Epidermal growth factor receptor targeting in cancer: A review of trends and strategies. Biomaterials 34:8690-8707, 2013

45. Yoshino $\mathrm{Y}$, Ishioka C: Inhibition of glycogen synthase kinase-3 beta induces apoptosis and mitotic catastrophe by distupting centrosome regulation in cancer cells. Sci Rep 5:13249, 2015 